\title{
ESPAÇO ESCOLAR: POSSIBILIDADES PARA PRÁTICAS DE ATIVIDADES FÍSICAS DA COMUNIDADE
}

\author{
ESPACIO ESCOLAR: POSIBILIDADES PARA PRÁCTICAS DE ACTIVIDADES \\ FÍSICAS DE LA COMUNDIDAD
}

\author{
SCHOOL SPACE: POSSIBILITIES FOR PRACTICES OF PHYSICAL ACTIVITIES OF \\ THE GROUP
}

\author{
Francisco Marcelo Catunda de OLIVEIRA ${ }^{1}$ \\ Paulo Adriano SCHWINGEL ${ }^{2}$ \\ Pergentina Parente Jardim CATUNDA ${ }^{3}$ \\ José de Caldas SIMÕES NETO ${ }^{4}$
}

RESUMO: A intencionalidade deste estudo é identificar nas escolas Públicas Estaduais de Tempo Integral da Cidade de Juazeiro do Norte - CE, os espaços para a prática de atividades físicas pela comunidade escolar em momentos extra-aula. Realizou-se uma pesquisa qualitativa de análise de discurso, de campo e experimental, em que foram utilizadas entrevistas a fim de seguir um roteiro com quatro gestores, nos quais se enfatizou a atividade física na escola como possibilidade de mudança de hábitos saudáveis, bem como os recursos disponíveis na escola para a prática de atividade física. Concluiu-se que é de primordial importância o uso dos espaços escolares para prática de atividades físicas pela comunidade e que a escola tem um poder de mudança de hábitos porque é lá que se desenvolve todo o intelecto e não dissociando corpo e mente, podemos também entender que esse espaço pode contribuir com uma cultura de saúde.

PALAVRA-CHAVE: Saúde na escola. Atividade física. Participação comunitária. Educação em saúde.

${ }^{1}$ Centro Universitário Dr. Leão Sampaio (UNILEÃO), Juazeiro do Norte - CE - Brasil. Docente. Mestre em
Formação de Professores e Práticas Interdisciplinares pela Universidade de Pernambuco (UPE). Possui Graduação
em Educação Física - Licenciatura Plena pela Universidade estadual vale do Acaraú (2004). ORCID:
<https://orcid.org/0000-0003-1124-0678>. E-mail: marcelocatunda@ hotmail.com
${ }^{2}$ Universidade de Pernambuco (UPE), Santo Amaro - CE - Brasil. Professor Permanente no Programa de Pós-
Graduação em ciências da Saúde (PPGCS) da UPE Campus Santo Amaro. Professor Colaborador no Programa de
Pós-Graduação em Ciências: Química da Vida e Saúde (PPGQVS) da UFRGS, e participa como especialista
convidado no Comitê Paralímpico Brasileiro (CPB). Doutor em Medicina e Saúde (PPgMS) na Faculdade de
Medicina da Bahia (FMB) da Universidade federal da Bahia. ORCID: <http://orcid.org/0000-0002-2935-3403>.
E-mail: paulo.schwingel@ upe.br
${ }^{3}$ Centro Universitário Dr. Leão Sampaio (UNILEÃO), Juazeiro do Norte - CE - Brasil. Docente. Mestra em
Formação de Professores e Práticas Interdisciplinares pela Universidade de Pernambuco (UPE), Campus, Petrolina
- PE. Com especialização em Gestão Educacional Pela Universidade Cândido Mendes. ORCID:
<http://orcid.org/0000-0002-5631-897X>. E-mail: pgjardim@ @otmail.com
${ }_{4}^{4}$ Centro Universitário Dr. Leão Sampaio (UNILEÃO), Juazeiro do Norte - CE - Brasil. Docente. Mestre em
Educação pela Universidade Estadual do Cariri (URCA). Especialista em Prática Docente do Ensino Superior,
pela Universidade Integradas de Patos, 2013. ORCID: <https://orcid.org/0000-0003-1036-2315>. E-mail:
ncaldas_22@hotmail.com 
RESUMEN: La intencionalidad de este estudio es identificar en las escuelas públicas estatales de tiempo completo de la Ciudad de Juazeiro do Norte - CE, los espacios para la práctica de actividades físicas por la comunidad escolar en momentos extra-lectores. Se realizó una investigación cualitativa de análisis de discurso, de campo y experimental, donde se utilizaron entrevistas a fin de seguir un itinerario con cuatro gestores, donde se enfatizó la actividad física en la escuela como posibilidad de cambio de hábitos saludables, así como los recursos disponibles en la escuela para la práctica de la actividad física. Se concluyó que es de primordial importancia el uso de los espacios escolares para la práctica de actividades físicas por la comunidad y que la escuela tiene un poder de cambio de hábitos porque es allí donde se desarrolla todo el intelecto y no disociando cuerpo y mente, podemos también entender que ese espacio puede contribuir con una cultura de salud.

PALABRAS CLAVE: Salud escolar. Actividad física. Participación de la comunidad. Educación en salud.

ABSTRACT: The intention of this study is to identify the spaces for the practice of physical activities by the school community in extracurricular moments in the State Public Schools of Juazeiro do Norte - CE. A qualitative research of speech, field and experimental analysis was carried out, where interviews were used to follow a script with four managers, which emphasized the physical activity in the school as a possibility of changing healthy habits, as well as the resources school to practice physical activity. It was concluded that it is of primary importance the use of school spaces for the practice of physical activities by the community and that the school has a power to change habits because it is there that develops all the intellect and not dissociating body and mind, that this space can contribute to a health culture.

KEYWORDS: School health. Physical activity. Community participation. Health education.

\section{Introdução}

O presente trabalho tem como tema Espaço Escolar: Possibilidades para práticas de atividades físicas. Nos dias atuais a sociedade vem passando por vários problemas relacionados a saúde uma vez que o sedentarismo e a má alimentação são algumas das causas desses transtornos que afetam a comunidade em geral, além de outros tais como, o uso de álcool, tabaco, cigarros etc. Podemos dizer a escola tem um papel fundamental na mudança de estilos de vida, uma vez que a escola pode estar presente em grande parte da vida desses alunos como é caso das escolas de Tempo Integral, utilizando dois turnos na qual o aluno terá que chegar as 7 horas e sair somente as 16 horas e 30 minutos aproximadamente.

Podemos dizer que estudos relacionados a conceitos da importância da atividade física na vida de escolares são bastante ricos, mas em contrapartida os trabalhos que envolvem 
intervenções na mudança de um estilo de vida mais ativo são poucos. Com isso podemos dizer que:

A necessidade de a Educação Física escolar assumir um explícito compromisso com a promoção da saúde, com destaque para o aumento da frequência semanal de aulas, a garantia de pelo menos $50 \%$ do tempo de aula com atividades físicas de intensidade no mínimo moderada e o uso de uma abordagem que contemple a todos os alunos, independentemente do nível de habilidades (SPOHR et al., 2014, p. 310).

A escola é um local dinâmico e nesse espaço as constantes reflexões proporcionam possibilidades de uma sociedade mais justa e igualitária. Podemos também apontar este ambiente como local de práticas de atividades físicas para promoção da saúde, como cita Marques e Gaya (1999, p.88) que "a escola é um local para prática de atividades físicas e de educação para saúde e, neste contexto a aula de educação física assume um papel privilegiado”. Porém a escola por si só não resolve todos os problemas de uma prática regular, outros momentos têm que ser proporcionados para um momento ativo, com isso a partir do momento que a escola também abre seus espaços para toda a comunidade possa desenvolver um estilo de vida ativo e saudável, a mesma está a contribuir de forma indireta para tal acontecimento, até porque uma cultura pode ser implantada de tal forma, que a imagem de um amigo é vista como uma complementação da autoridade paternal, como abordam Marques e Gaya (1999).

A escola apesar da dificuldade para tratar de temas como os de saúde, entende que uma reflexão sobre o assunto pode levar as crianças e adolescentes a desenvolverem uma aprendizagem compreendida como significativa, até porque são necessárias mudanças de hábitos e estilo de vida mais ativo, com isso, essa educação para a saúde terá que ser abraçada por todas as áreas do currículo escolar. Então estratégias terão que ser tomadas para que o currículo escolar possa ter uma flexibilidade, para que possamos entender os diversos problemas que afligem a sociedade e que a escola possa intervir de forma mais concreta. A escola de Tempo Integral tem a possibilidade de apontar essa flexibilidade de currículo, para que tenhamos um novo olhar da educação.

De acordo com estudos levantados pela Organização Mundial da Saúde (OMS, 2009), o sedentarismo é fator determinante na morte de $6 \%$ de toda a população mundial, assim superando até a obesidade com um valor de 5\%. Pensando neste contexto que a escola passa a ser o local mais adequado para desenvolver e reduzir ou até mesmo evitar esse percentual de mortes por inatividade, segundo Barbosa Filho (2016, p.18) algumas intervenções terão que ser tomadas, ele destaca algumas como a escola parece ser um ambiente apropriado para o desenvolvimento das principais ações de intervenções, sendo assim, o contexto escolar deverá 
ter projetos que possa intervir de forma exitosa na sua comunidade, uma vez que ela aponta suas necessidades, até porque a partir daí essa mesma comunidade possa mudar seu estivo de vida.

Esta pesquisa tem como principal objetivo é identificar nas escolas Públicas Estaduais de Tempo Integral da Cidade de Juazeiro do Norte - CE, os espaços para a prática de atividades físicas pela comunidade escolar em momentos extra-aula, para cumprir o objetivo verificou-se também se a escola encontra-se aberta a projetos que possa contribuir com uma comunidade escolar mais ativa, ou mesmo proporcionar uma atividade regular, a pesquisa mostrou se o ambiente educacional tem materiais e espaço para tal prática.

\section{Metodologia}

O Estudo tem como metodologia uma abordagem qualitativa de análise de discurso, integrada a uma pesquisa de campo, experimental e do tipo exploratória. Mattos, Rossetto Júnior e Blecher (2004, p.14) afirmam que pesquisa de campo é aquela em que as condições de controle das variáveis modificam com o ambiente e interferem na resposta.

A referida pesquisa foi feita nas escolas públicas Estaduais de Tempo Integral do município de Juazeiro do Norte na região do Cariri no Estado do Ceará. A quantidade de escolas de Tempo Integral da rede Pública Estadual na cidade de Juazeiro do Norte, são um total de 04 (quatro) escolas, na qual caracterizamos como ESCOLA 1, ESCOLA 2, ESCOLA 3 e ESCOLA 4, onde temos $100 \%$ da população e para a coleta de dados utilizamos roteiro para a entrevista, composto por questões abertas. Assim a pesquisa foi realizada com um representante da gestão escolar, das quatro escolas, onde todas estas têm um núcleo gestor composto por 01 (um) Diretor e 03 (três) Coordenadores Escolares, sendo o coordenador o foco da pesquisa.

\section{Resultados e Discussões}

Os resultados serão apresentados em cinco categorias, sendo elas: O espaço escolar, A escola e sua função na sociedade, $\mathrm{O}$ ensino médio em tempo integral, Prática de atividade física na escola e as condições dos materiais escolares. 
- Categoria 1: O espaço escolar

Os espaços escolares têm uma função na vida de seus alunos, construindo cenários nos quais os conhecimentos apreendidos nas diversas disciplinas tenham uma função ou contextualização lógica, com isso podemos compreender que o recinto escolar em uma dimensão também estrutural tem um significado importante na aprendizagem e desenvolvimento cultural de seus entes.

Cada profissional que trabalha com educação deve repensar constantemente sua função no que tange sua contribuição no processo ensino-aprendizagem, então reavaliar o uso dos ambientes escolares como parte desse processo é garantir a aprendizagem de todos e que essa ação tem como papel da gestão escolar.

Quando indagado para ESCOLA 3 sobre a utilização de seus espaços durante o final de semana pela comunidade, o coordenador entrevistado fala que esse espaço está aberto, mas com ressalvas, horários e espaços limitado de utilização, como aponta a seguir: "Tem condições, mas no momento não estamos cedendo para a comunidade devido não termos organizados os espaços, só tem apenas um professor utilizando a quadra e não é cedido a noite", e quando feito a mesma pergunta a ESCOLA 1, ela deixa bem claro em relação a utilização desses espaços aos finais de semana pela comunidade dizendo que a mesma não utiliza porque tem outros projetos e que espaço a escola possui embora não tem recurso humano para cuidar, é percebido que a um desalinhamento na fala do gestor da ESCOLA 1 quando diz que não cede a escola para comunidade porque não tem recurso humano, uma vez que na mesma fala cede para um projeto de basquete como apresenta no discurso do gestor: "Não, ela já está aberta com outros projetos [...], não teria condição por falta de recursos humanos", segundo a Comunidade Educativa (CEDAC) (2017, p.10), “A estrutura física da escola, assim como sua organização, manutenção e segurança, revelam muito sobre a vida que ali se desenvolve ou que se quer desenvolver."

Os espaços escolares muita das vezes não são cedidos para sua comunidade por entender que esse local não vai ser bem cuidado e que esse ambiente será violentado na sua estrutura pedagógica devido má uso, então nos questionamos, o que seria um espaço pedagógico escolar? A Comunidade Educativa (CEDAC, 2017), fala que o gestor escolar não pode ficar com o discurso de não ter tempo para se envolver com a organização dos ambientes escolar devido está ocupado com as questões administrativas e que o primeiro passo seria entender que esses espaços também são ambientes pedagógicos. 
- Categoria 2: A escola e sua função na sociedade

Diante de um contexto de transformação que vivemos na área da educação, tentar entender a função social da escola como algo relevante para a sociedade, é fazer valer a e compreender a verdadeira importância da escola para a comunidade, haja vista que a escola ao longo do tempo vem sofrendo alterações no que reflete seus objetivos e funções, é perceptível que os conceitos para tal definição, já estão prontos e pouco discutidos e questionados com a comunidade escolar na qual deveria ter como parte, com isso não tem-se uma definição pronta mas uma tentativa de entender esse espaço como ambiente plural e concreto, Raab (2016) cita que os fenômenos no cotidiano escolar estão atravessados por intenção maior, que implica em uma função social e que, invariavelmente, interferem nos fenômenos outros que aparecem no dia a dia escolar.

Pensar a escola como local de ensino-aprendizagem para o cotidiano é também ver esse ensino como algo concreto e de movimento, como cita Comenius (1650) apud Lorenzato (2010), o ensino deveria dar-se do concreto ao abstrato, já Herbart apud Lorenzato (2010), coloca que começa pelo campo sensorial. Assim podemos dizer que a aprendizagem tem que ser concreta, algo que atenda os anseios da sociedade, tais como pesquisas divulgadas pelo Ministério da Saúde (2014) que revelam índices e apontam que mais da metade da população brasileira está obesa. Índices atuais apontam 52\%, onde antes os dados apontavam em 2013 em torno de $43 \%$. Então pensar em mudança de hábitos saudáveis, seria uma busca mais na raiz, então teríamos que pensar na escola como local de possibilidade de mudança desses hábitos, não só em relação a alimentação como também em mudança de uma vida mais ativa, onde a escola pudesse intervir de forma mais direta e fazendo valer sua função como citado acima.

As instalações da escola são fator essencial não só para Educação Física como também para que a comunidade, após desenvolver uma Educação de mudança de hábito, possa executar suas atividades físicas na escola, porque a escola também é um espaço social e da comunidade a qual circunda.

A escola ainda permanece como uma gota de óleo na água, parece que a escola não faz parte daquele contexto onde muitos componentes da sociedade não conseguem compreender a verdadeira função da mesma e nem a escola com seus representantes fazem com que a sociedade entenda essa função. A escola continua a olhar para si mesma, esquecendo que existe um mundo ao exterior dela, fazendo com que seus alunos continuem construindo situações distantes deste mundo, atividades voltadas para ela mesma (DELVAL, 2006). 
Devido conceber esse ambiente como um local vinculado somente a aprendizagem da sala de aula e que a escola não pode ser perturbado nesse momento, fazendo com que tenhamos olhares somente para esse tempo, com isso pensar uma ambiente de disseminação de conhecimento, também é saber que requer movimento e tudo que tem vida tem movimento, essa preocupação com o silêncio e que para aprender existe uma data com hora e segundos marcado, ainda não transcendeu, na pronuncia do gestor da ESCOLA 2 percebe-se que existe uma condição para ceder o espaço para algum projeto e que essa condição é que seja no momento fora do horário letivo dos alunos, indagamos a escola se teria condição através de uma parceria ofertar um projeto de prática de atividade física 03 (três) vezes na semana, e ela respondeu: "Sim, mas teria um detalhe, teria que sentar e ver os horários de forma que não prejudicasse o andamento normal regular da escola, [...]”, abre-se a percepção que em caso de possibilidade de implantação a escola está disposta.

- Categoria 3: O ensino médio em tempo integral

O novo ensino médio brasileiro tem como direcionamento as escolas de tempo integral uma vez que o Ministério da Educação (MEC), sinaliza como uma escola de qualidade, dentro de um formato flexível, atual, viável e adequado à sua necessidade, com isso tornando possível que os alunos possam se dedicar a atividades de cunho mais prático e aplicado. No estado do Ceará esta implantação de escolas em Tempo Integral não é diferente do que rege a cartilha em nível nacional, com isso podemos destacar alguns pontos, tais como as dimensões fundantes da prática educativa destas escolas, como aponta a Secretária de Educação do Estado do Ceará (SEDUC): "A escola deve ser concebida como uma comunidade de aprendizagem; A aprendizagem cooperativa deve ser o método pedagógico estruturante; e o protagonismo estudantil é um princípio imperativo para qualquer proposta de ensino médio." (CEARÁ, 2017).

O tempo nestas escolas é de fundamental importância, que também a partir desse novo formato, surgem novas discussões, porque uma vez aumentando a jornada escolar o papel não é só do professor, mas o papel da família e dos funcionários, ou seja, que agora o envolvimento no processo educativo passa a não ser mais singular e sim uma visão mais plural.

- Categoria 4: Prática de atividade física na escola

A escola tem um papel fundamental na mudança de hábitos dos seus educandos uma vez que aprendizagem se torna significativa, podemos dizer que houve aprendizagem. Então 
falar sobre saúde na escola é algo necessário, como aponta o Programa Saúde na Escola (PSE), programa que tem o MEC e o Ministério da Saúde como impulsionadores visando à integração e articulação permanente da educação e da saúde, proporcionando melhoria da qualidade de vida da população brasileira. O PSE pode se encaixar perfeitamente dentro da nova estrutura do ensino médio, uma vez que preza pela formação integral dos estudantes por meio de ações de promoção, prevenção e atenção à saúde (BRASIL, 2007).

Entendendo a escola como parte da transformação de uma sociedade ela deve estar aberta para uma cultura de prática de atividade física para toda a comunidade. A escola para que se torne deslumbrante deve se tornar em um espaço que seja vivo, onde esses mesmos espaços passem a ser sentidos e se tornem local de pertence. Esse mesmo espaço ao se abrir para comunidade pode nos trazer um melhor convívio, como cita Rios (2011) "o ambiente escolar [...] é um dos lugares que permite exercitar tal convívio". Então quando na entrevista perguntamos sobre o espaço da escola, referido está aberta para comunidade, foi percebido que na fala do gestor da ESCOLA 1, a escola não está aberta para comunidade, como segue a fala abaixo: "Não, ela já está aberta com outros projetos [...], não teria condição por falta de recursos humanos, porque espaço a gente tem [...]".

Podemos dizer também que de acordo com o último censo de 2015 do Instituto Brasileiro de Geografia e Estatística (IBGE) sobre saúde do escolar, relata estatisticamente que cerca de $72 \%$, ou melhor, a maioria dos escolares que frequenta o $9^{\circ}$ ano do ensino fundamental estão em escolas onde há quadra de esporte, em que podemos dizer que a estrutura física escolar que possui esse espaço é de extrema relevância para práticas de atividades físicas, uma vez que os adolescentes passem a ter acesso.

Estudos apontam que a percepção do ambiente escolar entre adolescentes quanto a frase "se os locais e matérias para prática de atividade física não estão disponíveis quando querem", $50 \%$ concordam com essa afirmativa e apenas $8 \%$ discorda muito (BARBOSA FILHO et al., 2016).

Das escolas entrevistadas todas apontam que tem espaço, mas esses espaços dependem de algum transtorno legal para utilizar ou não e outros não cedem devido temer a depredação desses locais, conforme fala dos coordenadores entrevistados. A ESCOLA 2 deixa bem claro quando coloca sobre a existência da solicitação prévia através de formulário próprio, na fala a seguir: "Sim, a escola tem condições e está aberta, agora assim, atualmente o que acontece, a comunidade reserva horários para usar a quadra, [...] é só reservar durante a semana, a gente tem formulários de reserva e deixa as autorizações com horários já definidos, então a comunidade pode reservar". 
Embora a gestão escolar apontasse em sua fala que a comunidade escolar utilizasse os espaços da escola para prática de atividade física, estudos feitos na cidade de Juazeiro do Norte - CE em escolas de Tempo Integral estadual quando perguntado para a comunidade escolar (pais, alunos, professores e funcionários) se ela utiliza os espaços da escola para prática de atividade física, 93,7\% afirmam que não usa o espaço escolar para tal prática e apenas 6,3\% utilizam este espaço (OLIVEIRA, 2018).

- Categoria 5: As condições dos materiais escolares

Segundo dados apontados do IBGE (2015), podemos dizer que as escolas possuem materiais para prática de atividades físicas, que indicam que cerca de $92 \%$ dos alunos da última série do ensino fundamental estudam em escolas brasileiras que possuem materiais esportivos com condições de uso. As instalações e os equipamentos são instrumentos essenciais para uma boa prática de atividade física, e também fundamental para uma Educação Física de qualidade. Algo que todo aluno tem direito, como é colocado no Manifesto Mundial de Educação Física (2000, p.39) quando cita o documento da UNESCO (1978) dizendo que "na Carta Internacional de Educação Física e Esporte, no seu Art. 5 ficou registrado que instalações e equipamentos adequados são elementos imprescindíveis para Educação Física e Esporte”. E que essa responsabilidade de materiais possa se estender aos vários seguimentos responsáveis por uma educação de qualidade, com isso a Fédération Internationale D'Éducation Physique (FIEP) conclui no seu Manifesto Mundial da Educação Física (2000, p.39) relatando “que, todos os responsáveis pelos processos de Educação Física devem empenhar-se na busca de instalações e meios materiais adequados para que não seja prejudicado nos seus objetivos".

A partir do momento que prezamos por uma educação de qualidade devemos nos preocupar com toda estrutura que possa envolver a melhor relação pedagógica, seja ela no âmbito da relação aluna escola, ou na relação escola e comunidade.

De acordo com a entrevista do referido trabalho, quando perguntado sobre recurso físico e material as escolas são unânimes em dizer que existe recurso sim, embora há necessidade de reposição, mas que a escola tem material sim, para prática de atividade física, na fala da ESCOLA 2 nos mostra que a escola está disponível na construção de qualquer projeto que possa envolver a comunidade escolar, e deixa claro que existem até outros materiais, embora seja de uso das aulas de Educação Física, como na fala a seguir: "Sim, a escola tem recurso material e físico como já comentado e os espaços abertos da 
escola que são muitos e recursos materiais teria bola, rede para vôlei, tem tatame para prática de Taekwondo, inclusive nós temos a prática de Taekwondo todo sábado as 15 horas da tarde tem aula de Taekwondo, é dado pelo um professor da escola, então tem material e eu considero que existe recurso material e físico na escola".

A mesma escola também fala que tem poucos praticantes desse projeto e que acredita que possa ser a falta de divulgação e quem pratica são só alguns alunos que estudam na escola. A abertura da escola para comunidade ainda leva alguns receios por parte dos gestores.

A segurança é um desses temores dos gestores, mas para outras atividades, como o uso dos recursos para prática de atividade física a própria comunidade poderia dá conta (DELVAL, 2006). A ESCOLA 4 deixa claro em sua fala que matérias são usados apenas para as aulas de Educação Física, ficando assim a fala "[...], temos recursos, embora a grande parte desses recursos são utilizados para Educação Física [...]”, podemos ver a preocupação do gestor da ESCOLA 4 com o recurso ser exclusivo para assuntos da escola.

\section{Considerações finais}

Diante do exposto, conclui-se que a importância de os espaços escolares estarem abertos para comunidade escolar, sendo de fundamental relevância que esses locais também sejam repletos ou recheados de atividades para o desenvolvimento de uma sociedade mais justa e igualitária. A escola é o melhor ambiente para desenvolver qualquer projeto, porque é nela que se exala as melhores possibilidades de mudança de uma sociedade, principalmente os males que afetam a saúde dos indivíduos, e é nesse contexto que se desenvolve capacidade de autonomia, ética, valores e atitudes, com isso, podemos dizer que para tornar-se uma sociedade que tenha hábitos saudáveis, a escola terá que fazer valer sua função, capacitando o indivíduo a compreender e agir diante dos problemas impostos pelo mundo globalizado.

Dessa forma constatou-se que os coordenadores percebem que esses espaços devam estar abertos e que a escola tem esses ambientes e materiais, mas de uma forma muito sutil percebe-se que esses mesmos gestores tem receio de abrir o espaço educacional para comunidade escolar, acreditando que caso esses espaços fiquem abertos eles não tem recursos humanos que possam cuidar e ao mesmo tempo abrir, mas como bem colocado por Rios (2011) quando diz, que "o ethos é a casa do homem [...] e uma delas é a escola [...]e que para respeitar implica reconhecer [...]", então pode-se dizer que esses espaços precisam ser reconhecidos e que nele possamos exercitar nosso convívio. 
Durante a coleta de dados percebeu-se que os gestores têm receio de acontecimentos desagradáveis, como por exemplo, a quebra da rotina da escola, que se cristaliza em cultura tradicional, e que abrir esses espaços poderiam ocasionar perturbações no ambiente de aprendizagem, contudo fica aqui aberto para novas pesquisas no que se trata as preocupações desses gestores em deixar aberto esses espaços a serem utilizados, uma vez que a abertura desses local seriam também ao mesmo tempo sinônimo de dar vida a escola.

Nesse ínterim, cabe ao gestor escolar traçar caminhos menos tempestuosos. Temos um desafio que é fazer dessa função uma função técnica-docente, em que as percepções e desejos de professores, alunos, pais, associação de bairros, entre outros segmentos jamais sejam esquecidas, que as visões administrativas economicistas não se apoderem dos ideais educacionais, e que esse último elemento esteja acima de todos, porque é dele que temos esperança de um mundo melhor.

Consideramos então que mais estudos acadêmicos devem tomar essa temática, como foco para que nos aprofundemos cava vez mais e entendamos a evolução dos estudos e ainda possamos ajudar no cotidiano das escolas e ainda no desenvolvimento de uma sociedade, capaz de entender e tomar decisões para tornar sua vida com menos doenças ou até mesmo livre delas.

\section{REFERÊNCIAS}

\section{BARBOSA FILHO, V. C. Intervenção voltada à Promoção da Atividade Física em estudantes de Escolas Públicas De Fortaleza, Ceará: Efeito e Variáveis Mediadoras. Florianópolis. Tese de Doutorado em Educação Física. Universidade Federal de Santa Catarina, 2016.}

BARBOSA FILHO, V. C. et al. Atividade Física e Ambiente Escolar: Discutindo práticas e percepção na adolescência. Curitiba: Appris, 87 p, 2016.

BRASIL. Secad - Educação Continuada. Ministério da Educação (Comp.). Programa Saúde nas Escolas. 2007. Disponível em: http://portal.mec.gov.br/expansao-da-rede-federal/194secretarias-112877938/secad-educacao-continuada-223369541/14578-programa-saude-nasescolas. Acesso em: 23 ago. 2018.

BRASIL. Ministério da Educação. Prazo de adesão para Escola em Tempo Integral vai até o dia 25. Site oficial. 2014. Disponível: http://portal.mec.gov.br/component/tags/tag/40361. Acesso em 15 jun. 2017.

BRASIL. Ministério da Saúde. Vigilância de fatores de risco e proteção para doenças crônicas por inquérito telefônico, Secretaria de Vigilância em Saúde, Departamento de Vigilância de Doenças e Agravos não Transmissíveis e Promoção da Saúde. - Brasília: Ministério da Saúde, 2015. 
CEARÁ. Escolas Regulares em Tempo Integral na Rede Estadual de Ensino. Secretaria De Educação do Estado do Ceará, 2016. Disponível:

http://www.seduc.ce.gov.br/index.php/projetos-e-programas?id=10229:escolas-regulares-emtempo-integral-na-rede-estadual-de-ensino. Acesso em 17 de jun. 2018.

CEDAC. O que revela o espaço escolar? Um livro para diretores de escola. Comunidade Educativa CEDAC, 2. Ed. São Paulo: Moderna, 2017.

\section{FEDERAÇÃO INTERNACIONAL DE EDUCAÇÃO FÍSICA. Manifesto Mundial da Educação Física. Paraná, 2000.}

\section{INSTITUTO BRASILEIRO DE GEOGRAFIA E ESTATÍSTICA. Pesquisa nacional de} saúde do escolar: Coordenação de População e Indicadores Sociais. Rio de Janeiro: IBGE, 2016.

\section{LORENZATO, S. coord. O laboratório do ensino de matemática na formação de} professores. Autores Associados, São Paulo, 2010.

MARQUES, A. T; GAYA, A. Atividade física, aptidão física e educação para a saúde: estudos na área pedagógica em Portugal e no Brasil. Revista Paulista de Educação Física, v. 13, n. 1, p. 83-102, 1999.

\section{MATTOS, M. G.; ROSSETO JÚNIOR, A. J.; BLECHER, S. Teoria e prática da}

metodologia da pesquisa em educação física: construindo sua monografia, artigo científico e projeto de ação. Phorte, 2004.

OLIVEIRA, F. M. C. A escola pública como recurso da comunidade para prática de atividade física. 2018. 109 f. Dissertação (Mestrado) - Curso de Programa de Pós-graduação em Formação de Professores e Práticas Interdisciplinares, Universidade de Pernambuco UPE, Petrolina, 2019.

\section{ORGANIZAÇÃO MUNDIAL DE SAÚDE [OMS]. Global health}

risks: mortality and burden of disease attributable to selected major risks. Geneva: World Health Organization, 2009.

PORTAL BRASIL. Metade dos brasileiros está com excesso de peso. 2015. Disponível: http://www.brasil.gov.br/saude/2015/04/metade-dos-brasileiros-esta-com-excesso-de-peso. Acesso em 15 de maio. 2019.

RAAB, Y. S. Escola Para Quê?: Reflexões sobre a função da Escola Pública Estadual Paulista. Piracicaba. Dissertação de Mestrado em Educação. Universidade Metodista de Piracicaba, 2016.

RIOS, T. A. O espaço físico da escola é um espaço pedagógico. Revista Nova Escola, 2011. Disponível em: https://gestaoescolar.org.br/ onteúdo/476/o-espaco-fisico-da-escola-e-umespaco-pedagogico. Acesso em 17 de maio 2019. 
SPOHR, C. et al. Atividade física e saúde na Educação Física escolar: efetividade de um ano do projeto "Educação Física". Revista Brasileira de Atividade Física \& Saúde, v. 19, n. 3, p. 300, 2014.

\section{Como referenciar este artigo}

OLIVEIRA, Francisco Marcelo Catunda de; SCHWINGEL, Paulo Adriano; CATUNDA, Pergentina Parente Jardim; SIMÕES NETO, José de Caldas. Espaço escolar: possibilidades para a prática de atividades físicas da comunidade. Revista on line de Política e Gestão Educacional, Araraquara, v. 23, n. 2, p. 466-477, maio/ago., 2019. E-ISSN:1519-9029. DOI: 10.22633/rpge.v23i2.12653

Submetido em: 10/03/2019

Revisões requeridas: 15/04/2019

Aprovado em: 06/05/2019

Publicado em: 09/06/2019 